\title{
Momento Duolingo: um projeto do Campus Pinhais do Instituto Federal do Paraná
}

\section{Momento Duolingo: a project from the Pinhais Campus of the Federal Institute of Parana}

Luciana Pereira Jasinski Vieira1

\begin{abstract}
Resumo
A pesquisa teve como objetivo a análise do uso do aplicativo Duolingo como elemento que contribui para a aprendizagem de língua inglesa, com estudantes do Ensino Médio do Campus Pinhais do Instituto Federal do Paraná. A motivação do estudo foi a análise da evolução dos alunos fazendo uso de uma ferramenta alternativa ao estudo tradicional de sala de aula, por meio de um software educativo gamificado. A escolha do aplicativo em questão se deu por evidências fundamentadas em pesquisas de que há efetividade na aprendizagem por meio dessa ferramenta (como estudos de Grego; Vesselinov (2012); Barros et al. (2016); Alves, Santana e Silva (2016), entre outros). Os alunos foram convidados a participar do projeto, que envolvia as aulas virtuais do aplicativo e a resolução de suas dúvidas e prática de oralidade em encontros presenciais com a docente responsável no campus. Com início em abril de 2019, o projeto teve a adesão de 81 alunos. Por meio de uma ferramenta do aplicativo, os discentes compartilhavam seu progresso em uma sala virtual criada para o projeto - o que permitia que a docente pesquisadora tivesse total acesso aos seus desempenhos, além de poder propor tarefas e desafios. Ao longo do processo, percebeu-se a ferramenta como um elemento de motivação dos alunos, especialmente por conta do caráter de competição gerado pelo aplicativo. Por outro lado, relatos informais negativos dos alunos se embasaram principalmente em críticas ao caráter repetitivo das lições, que as deixaria "maçantes". A falta de naturalidade e autenticidade nas atividades também torna 0 aplicativo passível de críticas. 0 andamento do projeto foi apresentado na Mostra Cientifica do Campus Pinhais, com a apresentação de um aluno do campus, reforçando o caráter científico do projeto. 0 objetivo final do projeto é a divulgação de suas atividades e resultados à comunidade acadêmica via publicação em revista científica.
\end{abstract}

Palavras-chave: Duolingo. Ensino. IFPR.

\begin{abstract}
The research aimed at analyzing the use of the application Duolingo as an element to support English language learning, with high school students from the Pinhais Campus of the Federal Institute of Parana. The motivation for the study was the analysis of students' evolution through the use of an alternative tool to the traditional studies in class, making use of a gamified educational software. The choice for this application was based on research evidence on the effectiveness of learning through this tool (in studies by Grego; Vesselinov (2012); Barros et al (2016); Alves, Santana e Silva (2016), among others). Students were invited to take part in the project, which involved the application's virtual classes and asking questions plus speaking practice in physical meetings with the responsible teacher on campus. The project started in April 2019 and admitted 81 students. Through an application tool, learners shared their progress in a virtual class created for the project - which allowed the researcher teacher to have full access to their performances, and to propose tasks and challenges. Along the process, it was noticed that the tool was an element of motivation to the students, especially because of the competition created by the application. On the other hand, negative informal reports from students criticized the repetitive nature of lessons, which made them tedious. The lack of spontaneity and authenticity in the activities also make the application subject to criticism. The progress of the project was presented at the Scientific Conference of the Pinhais Campus, with a presentation by one of the students, reinforcing the scientific character of the project. The final aim of the project is the diffusion of its activities and results to the academic community through the publication in a scientific magazine.
\end{abstract}

Keywords: Duolingo. Teaching. IFPR.

1 Mestre em Linguística. Instituto Federal do Paraná, Pinhais, Paraná, Brasil. Orcid: https://orcid.org/0000-0003-4337-3555. E-mail: luciana.vieira@ifpr.edu.br.

LínguaTec, Instituto Federal de Educação, Ciência e Tecnologia do Rio Grande do Sul, Bento Gonçalves v. 6, n. 1, p. 100-108, jun. 2021. 


\section{Introdução}

O foco da pesquisa em questão foi a análise do uso de uma plataforma de ensino popular e com elementos de gamificação em turmas do Ensino Médio técnico do Instituto Federal do Paraná (IFPR) Campus Pinhais. Para tal, foi feito uso do aplicativo Duolingo, por conta de sua propagandeada eficiência, sua popularidade (mais de 200 milhões de usuários) e sua gratuidade. Por meio de uma ferramenta do aplicativo, a Duolingo for schools, o docente tem condições de criar uma sala e convidar alunos a dela participarem, ou divulgar o código de acesso à sala para que os alunos entrem. Já de início, os alunos fazem um nivelamento, e, a partir daí, o professor regente já pode iniciar suas observações a respeito do nível dos alunos, além do progresso, a motivação, a competição e a perseverança dos estudantes no uso do aplicativo.

A escolha de trabalhar com o Duolingo se deu também por conta da característica do alunado do campus - basicamente adolescentes - e sua natural inclinação por tecnologias de aprendizado que sejam divertidas e eficientes. Nesse aplicativo, os alunos aprendem ganhando pontos pelas respostas corretas e podem prestar corridas contra o tempo para "subir de nível", evoluir. As lições são curtas e personalizadas ao longo da evolução dos alunos. As aulas são desbloqueadas quando os alunos adquirem com sucesso as habilidades e conteúdos necessários para o progresso (plataforma gamificada).

Há diversas ferramentas motivadoras no aplicativo, como pontos; competição amigável entre os colegas; nivelamentos; mensagens de encorajamento; aquisição de "pedras preciosas" ("lingots"), a serem usadas em bônus do jogo; contagem de dias seguidos em que a língua foi praticada; pontuação de fluência (que usa informações da lição para medir o aprendizado); e troféus.

Dessa forma, intencionou-se motivar e engajar os alunos para que concluíssem as lições com sucesso, e que evoluíssem no aprendizado da língua inglesa de uma forma alternativa e lúdica.

\section{0 projeto "Momento Duolingo"}

O projeto de pesquisa aqui descrito foi conduzido por uma das docentes de Língua Inglesa do campus Pinhais do IFPR, que também coordenou o trabalho. A pesquisa se alimentou de dados fornecidos pela participação dos alunos na sala "Momento Duolingo", criada no Duolingo for schools. A divulgação inicial do projeto foi feita por meio de postagens no perfil da docente responsável e pelo perfil da Biblioteca do campus via rede social, além da colagem de cartazes chamativos e bem-humorados 
nos murais da escola, na biblioteca e na sala de entrada da Sessão Pedagógica do Campus. Uma nota a respeito do projeto também foi publicada no boletim informativo do IFPR.

Ao término do prazo estabelecido e divulgado no cartaz, a lista de alunos interessados contava com apenas cinco participantes. Como almejava-se atingir um público maior (ao menos 15 alunos), surgiu nesse momento a ideia de propor que o desempenho dos estudantes nas aulas do aplicativo pudesse ser fator contribuinte dos seus conceitos na disciplina de Língua Inglesa no quarto bimestre do ano. A divulgação foi feita de forma mais intensiva e um acompanhamento especial foi feito em duas turmas do terceiro ano e uma do quarto ano do Ensino Médio, por facilidade de acesso e comunicação da professora responsável pelo projeto, por ser regente nessas classes.

Após a divulgação nas turmas, a sala criada para o Momento Duolingo no aplicativo passou a ser composta por 51 alunos. Os dados deles foram observados com o objetivo de avaliar uma experiência prática do uso do aplicativo Duolingo.

Um aluno muito engajado no projeto e motivado a fazer os desafios do Duolingo aceitou o convite da professora pesquisadora desta proposta para relatar os resultados parciais da pesquisa na Mostra de Produção Científica da Educação Profissional e Tecnológica do Campus Pinhais, o que ajudou a dar ainda mais visibilidade e promoveu mais adesões ao projeto (que encerrou com 81 participantes).

Com o passar dos bimestres, alunos foram desenvolvendo suas lições no Duolingo com maior ou menor determinação, dentro de suas possibilidades de tempo e engajamento pessoal. Ao término do quarto bimestre, foram avaliados de acordo com sua evolução e progresso ao longo do ano letivo, recebendo seus conceitos proporcionalmente a esse afinco. Uma conversa informal com as turmas também ocorreu, com o objetivo de conhecer as percepções dos estudantes com relação ao projeto e para repensar um formato futuro para uso do Duolingo como apoio à sala de aula de Língua Inglesa regular.

\section{Revisão de Literatura}

O uso de ferramentas virtuais para a aprendizagem de línguas tem sido um vasto objeto de análise para pesquisas. Especificamente sobre o Duolingo, nos Estados Unidos, um estudo de professores da City University of New York (CUNY) e da University of South Carolina concluiu que no uso do aplicativo por 34 horas, os alunos aprendem o equivalente a um semestre de instrução da língua na universidade (GREGO; VESSELINOV, 2012). Este dado é orgulhosamente divulgado pela própria ferramenta. 
No Brasil, um trabalho conduzido por acadêmicos do curso de Licenciatura em Letras no Amapá analisou o uso do Duolingo com alunos de Ensino Médio de uma escola estadual e relatou o interesse dos alunos nas novas tecnologias. Os pesquisadores observaram ao longo do trabalho que a estrutura gamificada da ferramenta está ligada a "um fator importante no processo de aquisição de uma segunda língua: a motivação" (BARROS et al., 2016, p. 8). Os mesmos autores observaram, por meio de seus dados, que antes do projeto, $67 \%$ dos alunos não tiveram ou não tinham contato com a língua inglesa fora das aulas tradicionais, e ao término, 100\% deles percebiam que a plataforma Duolingo melhoraria 0 conhecimento de uma segunda língua.

Segundo os autores,

No que diz respeito aos vários benefícios que a língua inglesa pode obter ao incluir os recursos tecnológicos, está a maior possibilidade de metodologias para desenvolver as habilidades de listening (ouvir), speaking (falar), reading (ler) e writing (escrever), que são tão necessárias a quem deseja falar a língua. Observou-se então que o uso dos softwares é uma opção, pois, com seus variados recursos e suas versões para dispositivos móveis podem vir auxiliar o professor a trabalhar determinada habilidade com seus alunos (Barros et al., 2016, p. 3 e 4).

Em sua conclusão, observaram que o Duolingo atraiu a atenção "de forma positiva" e a plataforma se mostrou "interessante e qualificada (...) tanto dentro quanto fora da sala de aula, proporcionando o melhor desempenho e aquisição da língua inglesa" (p. 5). De nossa experiência com o Momento Duolingo nas turmas de Ensino Médio do IFPR, pode-se afirmar o mesmo. A gamificação engajou os alunos em uma saudável competição, em que todos fazem mais e mais lições com o objetivo de alcançar seus colegas, e o aprendizado se fortalece durante essa disputa.

Colegas do Instituto Federal do Sertão Pernambucano desenvolveram uma pesquisa intitulada "Uso do aplicativo Duolingo: uma forma inclusiva de ensinar e aprender línguas". Aproveitando-se da popularidade dos smartphones, utilizaram-nos para driblar a defasagem tecnológica característica da maioria das escolas brasileiras e para valer-se de "um novo paradigma educacional, o mobile learning" (ALVES; SANTANA; SILVA, 2016, p. 1). Em seu estudo qualitativo, buscaram mostrar o potencial do Duolingo como mecanismo de inclusão no ensino de línguas, auxiliando professores e beneficiando a interação com os alunos. Segundo os autores, foi observada a eficácia da utilização do aplicativo em vários níveis de ensino. Eles fazem uma ressalva, porém, quanto à falta de diálogos no aplicativo, o que resultaria em um usuário que "nem sempre estará apto a ter um bom diálogo com um nativo do inglês" (p. 4). Segundo eles, por esse e outros motivos, o Duolingo deveria funcionar como uma ferramenta agregadora no processo de aprendizagem, "sem, no entanto, substituir o processo central do ensino" (p. 4). Por fim, os pesquisadores convocam a comunidade científica para que divulguem pesquisas que 
estimulem professores e estudantes ao uso produtivo da internet na educação. Por conta dessa referida "falta de diálogos", ao se propor o projeto Momento Duolingo, tomou-se o cuidado de ofertar também momentos presenciais, ocasiões em que os alunos tinham a oportunidade de praticar a língua de forma oral e espontânea, sem as estruturas preestabelecidas almejadas pelo aplicativo.

O fato do Duolingo ser uma plataforma gamificada é, com efeito, um elemento motivador para os estudantes. Os estudos de James Paul Gee (2008) apontam os games como uma mídia que pode favorecer a aprendizagem, tanto de língua quanto de outras áreas do conhecimento. Sykes e Reinhardt (2013) validaram em suas pesquisas as contribuições dos jogos sob a luz de áreas-chave para a aprendizagem de uma segunda língua, a saber: objetivos, interação, feedback, contexto e motivação.

No Brasil, Vilson Leffa, em seu artigo intitulado "Gamificação adaptativa para o ensino de línguas" (2014), apresentou a distinção entre a aprendizagem de um conhecimento e a aprendizagem como habilidade. Segundo o autor, quem aprende por meio de games estaria exercitando essas duas esferas, o que potencializaria sua efetividade. $O$ autor menciona o Duolingo, ferramenta que considera "um exemplo de sucesso de gamificação" (LEFFA, 2014, p. 1), mas que não permite adaptações por parte do professor e fortalece uma visão de língua fechada, sendo ela mais um "objeto de discussão do que instrumento de comunicação" (p. 1). Também chama a atenção para o fato de o aplicativo proporcionar exercícios de produção oral, mas que neles não haveria uma garantia de uma avaliação confiável. 0 pesquisador faz críticas contundentes ao fato de a língua-alvo ser apresentada de forma fragmentada e segmentada (palavras e frases) e critica a ênfase à tradução (que, segundo ele, faz o ensino de línguas "voltar aos seus primórdios" (p. 4)). Por fim, elogia a jogabilidade do sistema, mas afirma que "deixa muito a desejar em termos de conceito de língua, vista apenas como objeto de estudo e discussão e não como um instrumento de comunicação e ação social" (p. 11).

Daiane Neuls (2015), em seu trabalho de conclusão de curso de especialização intitulado "O uso de Softwares educacionais no Ensino da Língua Inglesa", realizou um estudo de caso com o aplicativo Duolingo. Mobilizou duas turmas de Ensino Médio com a intenção de analisar os estudantes fazendo uso de mídias educacionais. $\mathrm{O}$ uso do aplicativo foi feito no laboratório de informática da escola e os alunos foram convidados a criar seus acessos e iniciar as lições. Após o uso, eles responderam a uma pesquisa, que revelou que a totalidade deles percebia que a aprendizagem de língua inglesa por meio do Duolingo era mais significativa e que $94 \%$ deles avaliava positivamente o impacto da utilização de ferramentas digitais na motivação de aprender. A percepção geral dos estudantes foi que o uso do Duolingo foi divertido e facilitador da aprendizagem da língua inglesa. 
No Brasil, esta mesma percepção de que jogos podem favorecer a aprendizagem é observável no edital do Programa Nacional do Livro Didático - PNLD, pois solicita a inclusão e o uso de recursos audiovisuais, jogos eletrônicos educativos, simuladores e infográficos animados no material didático do Ensino Médio. Tal fato demonstra o cuidado em fornecer aos alunos do Ensino Médio, além do contato com a tecnologia, uma forma de ensino atrativa, divertida e cujo foco é, de fato, o aprendiz. Ainda segundo o edital,

a cultura digital tem promovido mudanças sociais significativas nas sociedades contemporâneas. Em decorrência do avanço e da multiplicação das tecnologias de informação e comunicação e do crescente acesso a elas pela maior disponibilidade de computadores, telefones celulares, tablets e afins, os estudantes estão dinamicamente inseridos nessa cultura, não somente como consumidores. Os jovens têm se engajado cada vez mais como protagonistas da cultura digital, envolvendo-se diretamente em novas formas de interação multimidiática e multimodal e de atuação social em rede, que se realizam de modo cada vez mais ágil (BRASIL, 2015, pp. 35-36).

O projeto conduzido no campus Pinhais e aqui relatado possuiu a característica de tirar proveito do potencial do universo digital, valendo-se de novos modos de promover a aprendizagem, a interação e o compartilhamento de saberes entre professores e estudantes.

\section{Resultados obtidos}

O projeto foi encerrado em dezembro de 2019 com a participação de 81 alunos adicionados à sala "Momento Duolingo", criada para o acompanhamento dos participantes. Percebeu-se um maior engajamento daqueles que eram alunos da professora coordenadora do projeto, talvez pelos frequentes lembretes a respeito da realização das atividades.

Dados fornecidos pelo próprio Duolingo, na sala criada para o projeto, mostram que os alunos em média se mantiveram ativos por 22 dias ao longo do período. Quatro alunos efetivaram sua entrada no aplicativo apenas uma vez, enquanto há registro de participantes que estiveram ativos 137, 156 e 108 vezes, por exemplo. 0 número de lições efetivadas também é fornecido, tendo sido os números mais significativos: 441, 452 e 796.

Relatos positivos dos alunos sobre o uso do aplicativo englobam: a praticidade; o fato de ter aprendido muito; o reconhecimento da ferramenta como um auxílio para passar a entender melhor o inglês; sua utilidade para relembrar e fixar vocabulário; boa didática; aprendizagem que flui com facilidade; o fato de trabalhar as quatro habilidades da língua; a importância das repetições e revisões 
constantes; a ludicidade da plataforma; o trabalho com a pronúncia; seu caráter intuitivo e motivador; e o fato de funcionar em diferentes plataformas.

As críticas recorrentes dos estudantes se referem ao fato de 0 aplicativo ser cansativo; não ser divertido; ser muito repetitivo (tanto que desmotiva); ter um início legal, mas com o tempo tornar-se cansativo; ter sido cobrado de forma mandatória; ter notificações constantes e irritantes; não ser aprofundado. Houve também críticas pela falta de contexto dos exercícios que poderiam ter mais de uma resposta, mas o aplicativo só aceitaria uma. Alunos também relataram falta de tempo para fazer as lições.

\section{Dificuldades encontradas}

Houve dificuldade inicial em compor a turma, que inicialmente objetivava 15 alunos, para 0 projeto. Isso foi contornado por meio de divulgação mais próxima aos alunos, com apresentação do projeto em sala de aula, e com a associação do engajamento nas lições com um conceito (nota).

Houve baixa frequência na parte presencial do projeto - proposta duas vezes na semana para sanar dúvidas e praticar o idioma em sua modalidade falada. Um motivo provável para isso é o fato de os alunos, durante as tardes, já estarem envolvidos em outros projetos e/ou dependências, pois o projeto se iniciou no mês de abril e eles já estavam engajados em outros compromissos. Isso também pode ter sido reflexo do caráter de autonomia propiciado pelo aplicativo, que é bastante intuitivo e fácil de usar. Como se propõe a trabalhar todas as habilidades da língua sendo aprendida, inclusive a fala, os alunos podem não ter se sentido motivados a participar da oportunidade de conversação proposta pelo projeto.

\section{Considerações finais}

Como desfecho do projeto, pode-se afirmar que como ferramenta complementar ao ensino, o Duolingo desempenha excelente função, pois sua plataforma gamificada motiva a maior parte dos alunos, e demonstra ser um bom instrumento para revisão de vocabulário e estruturas da língua. Porém, sua previsibilidade não reflete a espontaneidade do uso real de uma língua, o que pode ficar evidente para alunos ao fazerem uso cotidiano da língua em interações sociais e contextos reais.

Portanto, sugere-se que o aplicativo Duolingo possa ser proposto para uso em paralelo à sala de aula regular de língua inglesa. Com facilidade ao acesso de qualquer lugar e a qualquer momento, amplia a possibilidade de contato diário do aprendiz com a língua em estudo. Nele, os alunos podem fortalecer áreas como vocabulário, estrutura interna das sentenças e encontrar motivação para seguir 
aprendendo a língua. Não substitui, porém, um trabalho feito com contexto em sala de aula, que desenvolva o raciocínio e a criticidade dos alunos. Também não supre o trabalho feito com base em leitura e interpretação de texto, e não expõe os alunos a uma ampla gama de gêneros textuais, que os prepararia para o uso efetivo cotidiano da língua inglesa. Por fim, também deixa a desejar na habilidade de fala, pois não dá margem a espontaneidade e diversidade de respostas de um enunciado natural cotidiano.

Encerra-se o projeto com a certeza da validade da experiência e de que a ferramenta auxiliou os alunos que nela efetivamente se engajaram. Recomenda-se esse uso paralelo a outros professores de línguas que almejam dinamismo em suas metodologias complementares, e a ampliação de sua gama de atividades extras. Por fim, estende-se o convite para que outras instituições formais proponham trabalhos de uso concomitante do aplicativo Duolingo, e que seus resultados sejam divulgados à comunidade acadêmica, para que criemos um farto conjunto de pesquisas relevantes sobre o uso de softwares educacionais no ensino de línguas no Brasil.

\section{Referências}

ALVES, V. L. S.; SANTANA, J. S.; SILVA, J. de S. Uso do aplicativo Duolingo: uma forma inclusiva de ensinar e aprender línguas. In: II CONGRESSO INTERNACIONAL DE EDUCAÇÃO INCLUSIVA. 2016, Campina Grande. Anais... Campina Grande: Editora Realize, 2016. Disponível em: <http://www.editorarealize.com.br/revistas/cintedi/anais.php>. Acesso em: 19 de março de 2020.

BARROS, L. da R. B. et al. O uso da plataforma Duolingo como ferramenta de aprendizado da língua inglesa no LIED da Escola Estadual Prof. Gabriel Almeida Café. IESAP. Disponível em: <https://www.iesap.edu.br/arquivo/0\%20USO \%20DA\%20PLATAFORMA\%20DUOLINGO\%20COMO\% 20FERRAMENTA $\% 20$ DE $\% 20$ APRENDIZADO $\% 20$ DA $\% 20$ L $\%$ C3\%8DGUA $\% 20$ INGLESA $\% 20$ NO $\% 20$ LIED\%20DA\%20ESCOLA\%20ESTADUAL\%20PROF.\%20GABRIE\%20ALMEIDA\%20CAF\%C3\%89.pdf >. Acesso em: 15 mar. 2020.

BRASIL. Ministério da Educação (MEC). Fundo nacional de desenvolvimento da educação (FNDE) e Secretaria de Educação Básica (SEB). Edital de convocação para o processo de inscrição e avaliação de coleções didáticas para o programa nacional do livro didático PNLD 2015.

DUOLINGO. Quem somos. Disponível em: <https://www.duolingo.com/info>. Acesso em: 26 jan. 2020.

FRAGA, Nayara. Como o Duolingo chegou a 300 milhões de downloads sem propaganda nenhuma. REVISTA ÉPOCA NEGÓCIOS, São Paulo, 25 de out. 2018. Disponível em: $<$ https://epocanegocios.globo.com/Tecnologia/noticia/2018/10/como-o-duolingo-chegou-300-milhoesde-downloads-sem-propaganda-nenhuma.html>. Acesso em: 20 fev. 2020.

GEE, J. P. Learning and Games. 2008. Disponível em: <http://docslide.us/download/link/gee-learning>. Acesso em: 20 mar. 2020. 
GREGO, J.; VESSELINOV, R. Duolingo Effectiveness Study: final report. Disponível em: <http://static.duolingo.com/s3/DuolingoReport_Final.pdf>. Acesso em: 28 fev. 2020.

LEFFA, V. J. Gamificação adaptativa para o ensino de línguas. In: Congresso lbero-Americano de Ciência, Tecnologia, Inovação e Educação. Buenos Aires. Anais..., 2014, p. 1-12.

NEULS, D. E. O uso de Softwares educacionais no Ensino da Língua Inglesa. 2015. 45 p. Trabalho de conclusão de curso apresentado como requisito para obtenção do grau de especialista em Mídias na Educação - Universidade Federal do Rio Grande do Sul, Tio Hugo, 2015.

SYKES, J. M.; REINHARDT, J. Language at play: Digital games in second and foreign language teaching and learning. Boston: Editora Pearson, 2013.

Data de submissão: 20/02/2021. Data de aprovação: 08/04/2021. 